\title{
Laser Surface Processing of Hot Rolled Ni-45.0at.\%Ti Shape Memory Alloy
}

\author{
Chengpeng $\mathrm{Ma}^{1}$, Yingchun Guan ${ }^{1 *}$, Wei Zhou ${ }^{2}$ \\ ${ }^{1}$ School of Mechanical Engineering \& Automation, Beihang University \\ 37 xueyuan Road, Beijing 100191, P.R. China \\ ${ }^{2}$ School of Mechanical and Aerospace Engineering, Nanyang Technological University \\ 50 Nanyang Avenue, Singapore 639798, Singapore \\ *Email: guanyingchun@buaa.edu.cn
}

\begin{abstract}
Both oxide removal and low surface roughness was achieved at hot rolled Ni-45.0at.\%Ti shape memory alloy (SMA) surface using a nanosecond pulsed Nd:YAG laser. The oxidized and polished surfaces were analyzed by White-Light Interference (WLI), Focus ion beam (FIB) and energy dispersive spectrometer (EDS). Special attention was paid to investigate phase transformation evolution of SMA before and after laser irradiation using Differential scanning calorimeter (DSC) and $\mathrm{X}$-ray diffraction (XRD). Results revealed that the as-received oxides with thickness of 10 micron had been removed completely after laser treatment, and surface roughness of laser-treated surface was less than $1 \mu \mathrm{m}$. Moreover, no obvious change occurred for phase analysis and transformation temperatures of the SMA, indicating that the influence of laser irradiation on shape memory effect of hot rolled Ni-45.0at.\%Ti SMA was negligible.
\end{abstract}

DOI: $10.2961 /$ jlmn.2017.01.0002

Keywords: shape memory alloy, one-stop laser processing, oxide removal, surface roughness, transformation temperature, phase

\section{Introduction}

Ni-Ti shape memory alloy (SMA) have a wide range of applications due to shape memory effect (SME) and superplastic property, such as orthodontics, actuators and nanotweezer [1-3]. Hot working processes including forging and rolling have been recognized as crucial forming techniques for SMAs [4-5]. As an active element, Ti is always oxidized during hot working processes [6], and the oxides layer can be easily found at the initial surface of SMAs after hot treatment, which usually affect the SME of SMA. Therefore, it is required to remove oxides layer of the SMA for further applications. At the same time, surface roughness of the SMA should be maintained at low level to keep mechanical properties of workpieces or fit further processing.

Laser surface processing has been considered as a promising method to enhance surface properties of materials without altering or affecting bulk properties in numerous applications [7-8]. For example, laser cleaning has been developed to replace mechanical polishing and aggressive chemicals due to serious drawbacks of being expensive, poor quality control or a source of environmental pollution caused by these conventional cleaning methods. Particularly for metallic objects in industrial settings, laser is considered as an attractive tool for removal of particulate contaminants, oxide layers, oil, grease, etc. from the surface, as they are highly controllable and can be selectively applied [9-10]. Moreover, in recent years, laser polishing had been demonstrated to be an effective polishing method for metal materials such as iron, steel, and titanium alloys. Compared with manual mechanical polishing, laser polishing have advances in automation and surface integrity. Laser polishing is mainly based on melting caused by laser irradiation. When molten pool formed, flowing material tend to redistribute to a same horizontal level due to surface tension and gravity, then after quick solidification of molten pools, surface roughness would be reduced [11-13]. Laser polishing could be achieved by pulsed laser, continuous wave (CW) laser [14-16]. CW laser melt materials continuously, while pulsed laser melts material surface during each pulse and forms ripple structure. By adjustment of laser beam overlapping, pulsed laser could also produce a relatively smooth surface. Compared with CW laser, pulsed laser heat materials discretely and cause less heat accumulation. However, recent researches of laser polishing have not investigated about SMAs, which have some particular characteristics. Due to heat sensibility of SMAs, pulsed laser is more suitable for polishing this kind of material.

In this paper, we carry out a one-stop method to remove oxides layer of Ni-Ti SMA surface and achieve low surface roughness by nanosecond pulse laser. To study the effect of laser treatment on properties of SMA, by using SEM, EDS, XRD and FIB, we discuss how laser treatment affects surface phase compositions and of Ni-Ti SMA, DSC is used to investigate transformation temperatures. The aim of this study is to understand the effects of laser processing for $\mathrm{Ni}$ Ti SMA, and indicate how it applies for potential applications.

\section{Experimental Procedures}

\subsection{Materials}

Commercial Ni-Ti plate with a nominal composition of 45.0 Ti and 55.0 Ni with $0.6 \mathrm{~mm}$ thick was chosen, the alloy plate was hot rolled and without aging treatment. Specimens 
were cut to size of $10 \mathrm{~mm} \times 10 \mathrm{~mm}$ and $4 \mathrm{~mm} \times 5 \mathrm{~mm}$ for different measurements.

\subsection{Laser processing}

A nanosecond pulsed Nd:YAG laser (wavelength 1064 $\mathrm{nm}$, pulse duration $34 \mathrm{~ns}$, repetition rate $30000 \mathrm{~Hz}$, spot size $50 \mu \mathrm{m})$ was used in this study. The optimized average power density was $6.01 \times 10^{4} \mathrm{~W} / \mathrm{cm}^{2}$, and the optimized scanning speed was $500 \mathrm{~mm} / \mathrm{s}$ with $67 \%$ overlapping rate on scan direction. The irradiated area was as big as specimens using hatched scanning mode with $80 \%$ overlapping between scan lines in the program. Laser beam scanned three times to remove oxide layer and another two times for surface polishing. When laser was turned on, the specimen was placed under Ar gas protection.

\subsection{Surface Characterization}

Morphology and was observed by Carl Zeiss EVO MA15 scanning electron microscopy (SEM) with energy dispersive spectrometer (EDS) and KLA-Tencor MicroXAM-100 3D Surface Profilometer.

Cross section views of local area were prepared by FEI Helios 650 with focused ion beam (FIB) technology. The main parameters for ion cutting were chosen as $30 \mathrm{kV}, 47$ nA-0.79 nA, and 1.5 $\times 10-4$ Pa pressure. Average dimension of each hole was $(100-200 \mu \mathrm{m}) \times(40-80 \mu \mathrm{m}) \times(20-30 \mu \mathrm{m})$.

Surface crystal structure of the Ti-Ni alloys was examined by Bruker D8 ADVANCE X-ray diffractometer (XRD) with $\mathrm{Cu} \mathrm{K} \alpha$ radiation $(\lambda=0.15418 \mathrm{~nm})$ filtered by nickel. A part of specimens are manual polished to substrate for measuring original state phase.

\subsection{Transformation temperatures measurement}

Transformation temperatures of $\mathrm{Ni}-\mathrm{Ti} \mathrm{SMA}$ was measured by NETZSCH DSC 204F1 Phoenix differential scanning calorimeter. Size of specimens for DSC measurement was $4 \mathrm{~mm} \times 5 \mathrm{~mm}$.

\section{Experimental results and discussions}

\subsection{Effect of laser treatment on oxides removal}

Different from previous work, separate beam scanning during laser treatment was chosen to examine local effect of laser on oxides removal. After laser treatment, surface chemistry and cross-section view of laser-treated area at the SMA surface was examined carefully, as shown in Fig. 1 and Fig. 2. Fig. 1 shows a photo of laser treated region at the asreceived SMA surface.

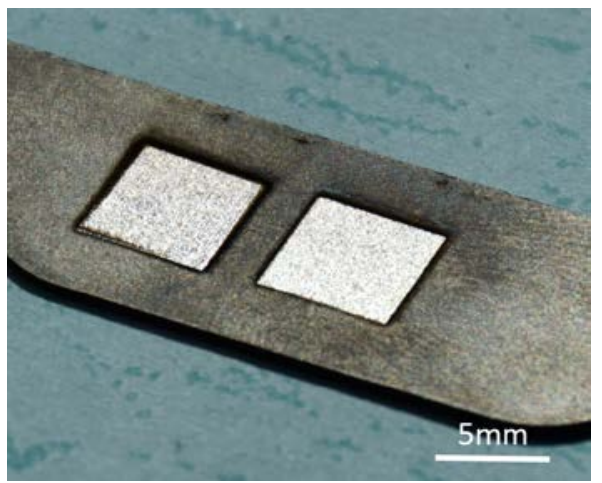

Fig. 1 Laser-treated region at as-received Ni-Ti SMA surface.
It can be found that oxygen content was dropped significantly at the irradiated area on basis of EDS element mapping data in Fig. 2. Oxygen content was more than $40 \%$ at untreated surface, and reduced to less than $3 \%$ at treated surface, as shown in Table 1. Results of EDS indicates that laser treatment has effectively removed the original oxide layer from as-received $\mathrm{Ni}$-Ti surface.
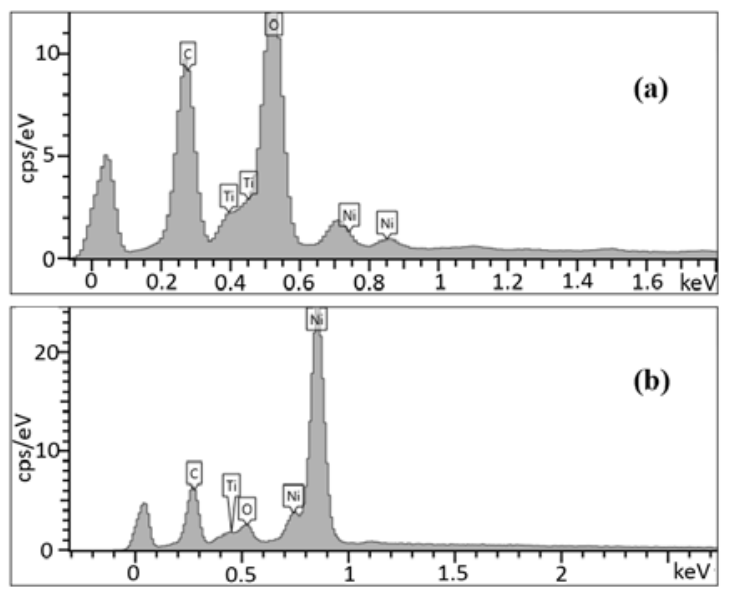

Fig. 2 EDS analysis of Ni-Ti SMA. (a) As-received surface (b) and laser-treated surface.

Table 1 Element contents of surfaces before and after laser treatment

\begin{tabular}{ccccc}
\hline Concentration(wt \%) & $\mathrm{Ti}$ & $\mathrm{Ni}$ & $\mathrm{O}$ & $\begin{array}{c}\text { Possible } \\
\text { composition }\end{array}$ \\
\hline Original & 53.28 & 3.78 & 42.95 & $\mathrm{TiO} 2$ \\
\hline Laser treated & 18.06 & 79.10 & 2.85 & $\begin{array}{c}\text { NiTi metal } \\
\text { compound, } \\
\mathrm{Ni}\end{array}$ \\
\hline
\end{tabular}

Continuous beam scanning for practical laser treatment was further performed, the top surface and cross section view of both as-received surface and laser-treated area are shown in Fig.3. Fig. 3(c) and (d) show that no oxides or contaminants layer was observed at laser-treated area, while melting and solidification occurred at the top surface. Fig. 2(b) suggests that the thickness of original oxides and contaminants layer at as-received surface was nearly 10 micron.

Fig. 4 shows XRD results of as-received and lasertreated Ni-Ti SMA alloy. In theory, original phase compositions of Ni-45.0at.\%Ti SMA in low temperature are $\mathrm{NiTi}$ (B2) and $\mathrm{Ni}_{3} \mathrm{Ti}$. Compared with the phases of substrate, phases of surface have increased in $\mathrm{Ni}_{3} \mathrm{Ti}$ and have a new phase of Ni. According to oxidation behavior theory of NiTi SMA, oxidized surface of $\mathrm{Ni}-\mathrm{Ti}$ has a multilayered structure, because of deposition of $\mathrm{Ni}$ during the oxidation process of surface NiTi phase [6]. There are 4 layers from surface to substrate, the first layer is probably pure $\mathrm{TiO}_{2}$, the second layer may be compose of $\mathrm{TiO}_{2}$, $\mathrm{Ni}$ and a little $\mathrm{Ti}$, the third layer could be composed of $\mathrm{Ni}$ and $\mathrm{Ni}_{3} \mathrm{Ti}$, and the substrate is the same as as-received material, as shown in Fig. 5. Considering phase compositions after laser treatment, we speculate that laser treatment removed the first two layers and the remained surface layer is the third layer which contain more pure-Ni phase. Meanwhile, it means laser treatment had not change phases of the remelting third layer. 


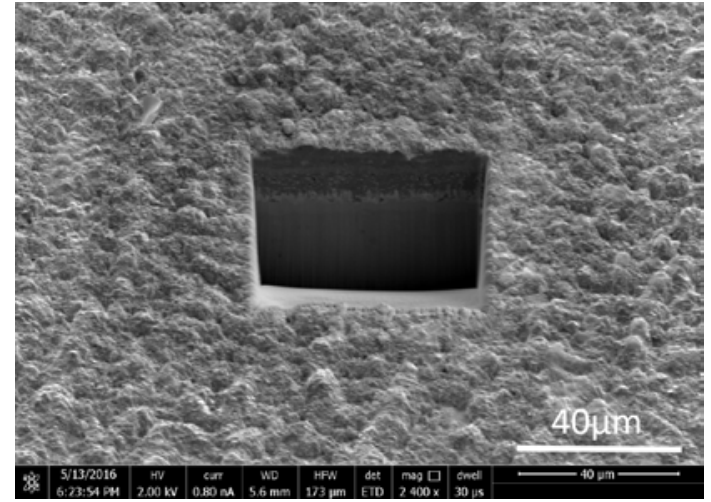

(a)

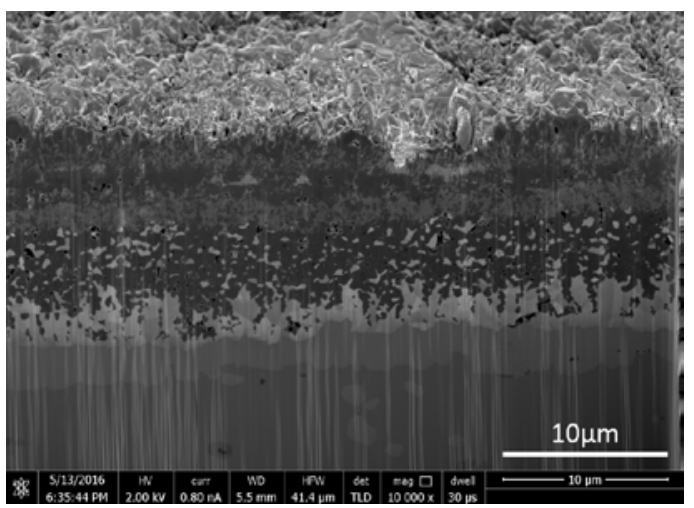

(b)

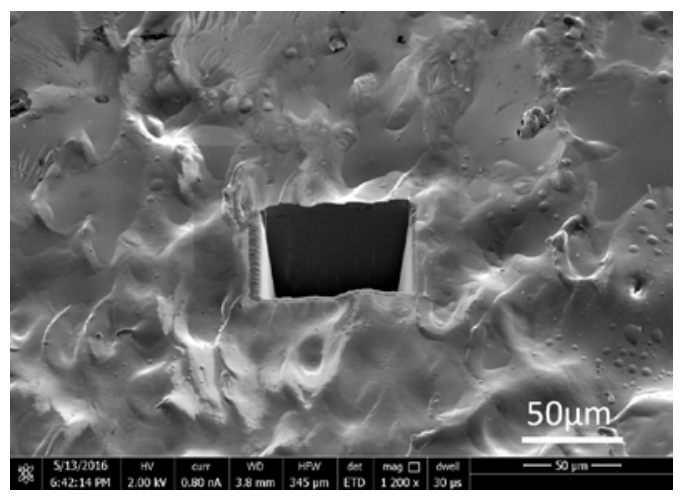

(c)

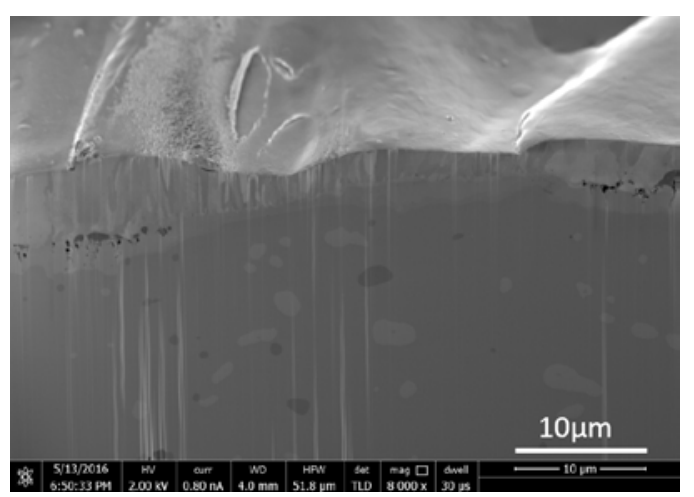

(d)

Fig. 3 Cross section of Ni-Ti SMA surface cut by FIB (a)(b) Asreceived surface (c)(d) laser-treated surface.

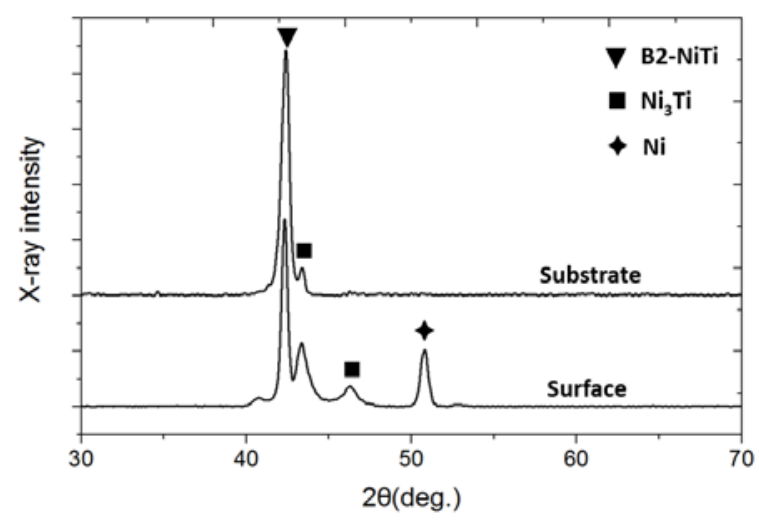

Fig. 4 XRD patterns of Ni-Ti SMA

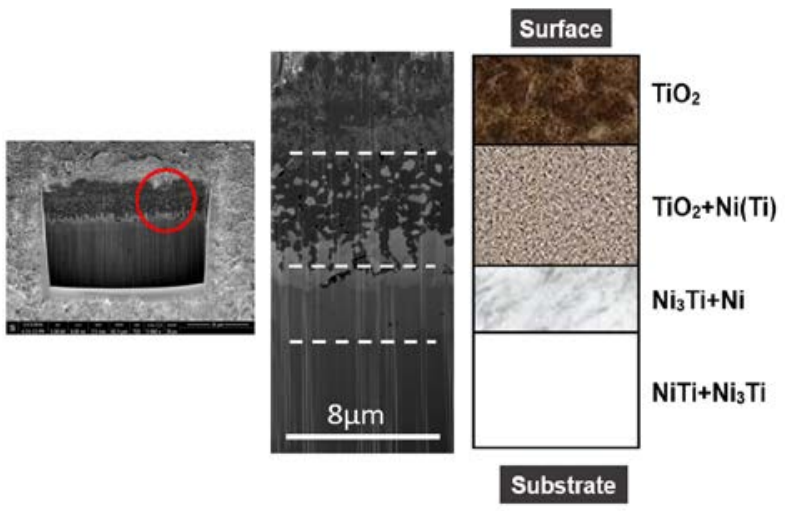

Fig. 5 Multi-layer structure of as-received oxidized surface

\subsection{Effect of laser treatment on surface morphology}

In this work, to reach a balance between oxides removal efficiency and keeping surface roughness, laser scanning model was hatched to be $80 \%$ overlapping and multiple scanning. As shown in Fig. 6, melting tracks are observed on surface of Ni-Ti SMA. Moreover, white-light interferometer was employed to measure surface topography and surface roughness of laser treated Ni-Ti SMA. Fig. 7 shows that after laser treatment, on most of the surface, peak-to-valley height of ripple structure was about $4-5 \mu \mathrm{m}$, and average roughness of the laser treated surface was measured as $0.9 \mu \mathrm{m}$.

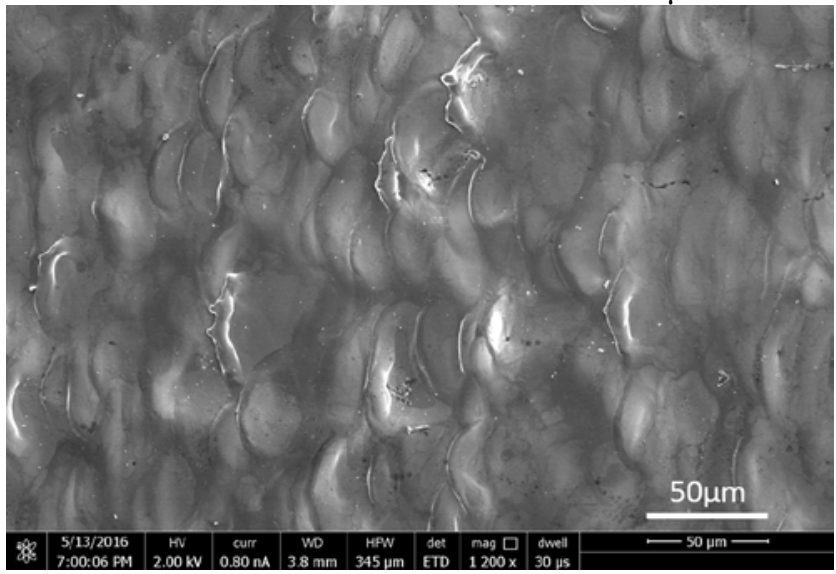

Fig. 6 Surface of Ni-Ti SMA after laser treatment. 


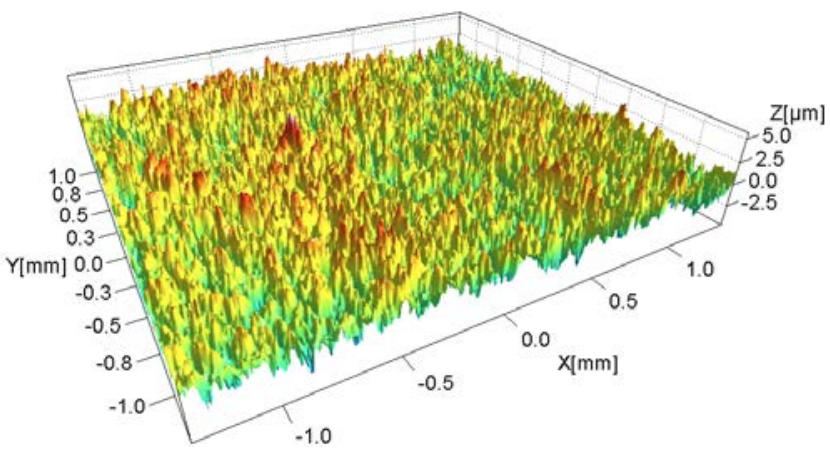

(a)

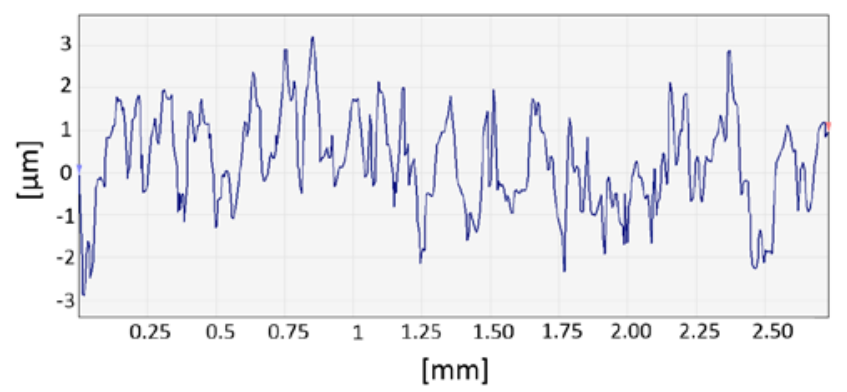

(b)

Fig. 7 (a) 3D surface profiles and (b) section profile of $\mathrm{Ni}-\mathrm{Ti}$ SMA.

\subsection{Effect of laser treatment on transformation temperatures of Ni-Ti SMA}

In order to investigating the influence of laser treatment on transformation temperatures of Ni-Ti SMA, as-received and laser treated Ni-Ti SMA sheets were aged at $450^{\circ} \mathrm{C}$ for $30 \mathrm{~min}$ and then measured transformation temperatures of the aged Ni-Ti sheets. DSC results obtained as a function of temperature for as-received and laser treated Ni-Ti SMA is shown in Fig. 8. For both cooling and heating circles, only slight shifts of the transformation temperatures are observed, and the differences are less than $5^{\circ} \mathrm{C}$. Therefore, it can be deduced that laser treatment of SMA surface have not changed transformation temperatures of the Ni-Ti SMA, and main phase of Ni-Ti SMA is also not changed after laser processing.

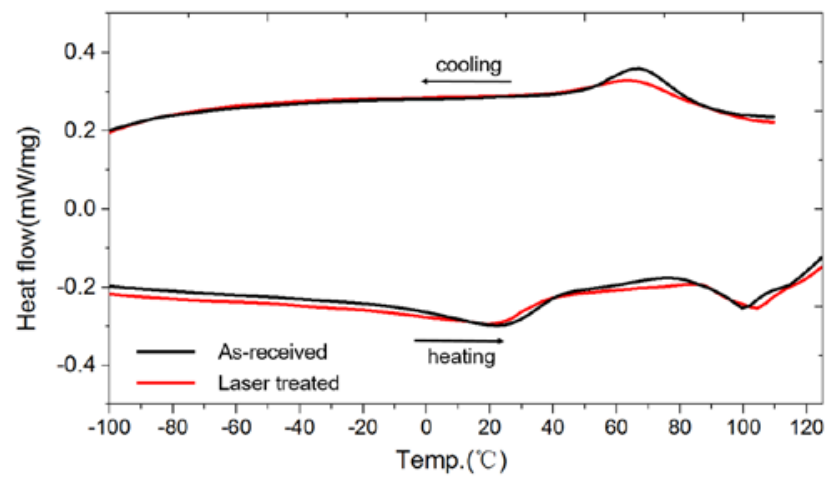

Fig. 8 DSC graph of Ni-Ti SMA before and after laser processing.

\section{Conclusion}

Analyses of Ni-45.0at.\%Ti shape memory alloy before and after laser processing was carefully examined. Thickness of as-received oxides has observed to be $10 \mu \mathrm{m}$. Oxide layer was completely removed and oxygen content was decreased significantly after laser treatment. Moreover, surface roughness of laser treated surface was measured as less than $1 \mu \mathrm{m}$. Phase compositions of the SMA sheet had no obvious change after laser treatment. In addition, there was no significant change on transformation temperatures of $\mathrm{Ni}$ Ti SMA sheets.

\section{Acknowledgments}

Support by the National Program of Key Research in Additive Manufacturing and Laser Manufacturing of China with grant number 2016YFB1102503, National Key Basic Research Program of China with grant number 2015CB059900, Beijing Natural Science Foundation with grant number 3162019, Fundamental Research Funds for the Central Universities from Beihang University with project code 74003401.

\section{References}

[1] L. Zhang, C. Xie, and J. Wu: Mater. Sci. Eng. A, 25, (2006) 905.

[2] E. Teodorescu, E. Galan, S. Milicescu, R. Pascu, and I. Ionescu: Metalurgia Int., 15, (2010) 19.

[3] P.V. Lega, V.V. Koledov, D.S. Kuchin, P.V. Mazaev, A.M. Zhikharev, A.V. Mashirov, V.S. Kalashnikov, S.A. Zybtsev, V.Ya. Pokrovskii, V.G. Shavrov, V.A. Dikan, L.V. Koledov, A.V. Shelyakov, and A.V. Irzhak: J. Commun. Technol. Electron., 60, (2015) 1124.

[4] Y. Zhu, X. Wang, L. Wang, Y. Fu, J. Qin, W. Lu, and D. Zhang: Mater. Sci. Eng. C, 32, (2012) 126.

[5] Y. Facchinello, V. Brailovski, S. D. Prokoshkin, T. Georges, and S. M. Dubinskiy: J. Mater. Process. Technol., 212, (2012) 2294.

[6] C.H. Xu, X.Q. Ma, S.Q. Shi, and C.H. Woo: Mater. Sci. Eng. A, 371, (2004) 45.

[7] A. Kum, M. Sapp, J. Vincelli, and M. C. Gupta: J. Mater. Process. Technol., 210, (2010) 64.

[8] Y.C. Guan, G.K.L. Ng, H. Y. Zheng, M.H. Hong and Z. Zhang: Appl. Surf. Sci., 270, (2013) 526.

[9] S. Costil, A. Lamraoui, C. Langlade, O. Heintz, and R. Oltra: Appl. Surf. Sci., 288, (2014) 542.

[10]G.X. Chen, T.J. Kwee, K.P. Tan, Y.S. Choo, and M.H. Hong: J. Laser micro/nanoeng., 7, (2012) 249.

[11]F.E. Pfefferkorn, N.A. Duffie, J.D. Morrow, and Q. Wang: CIRP Ann-manuf. Technol., 63, (2014) 237.

[12]E.V. Bordatchev, A.M.K. Hafiz, and O.R. TutuneaFatan: Int. J. Adv. Manuf. Technol., 73, (2014) 35.

[13]A. Lamikiz, J.A. Sanchez, L.N.L. Lacalle, and J.L. Arana: Int. J. Mach. Tool. Manuf., 47, (2007) 2040.

[14]C. Nüsser, H. Sändker, and E. Willenborg: Phys. Procedia, 41, (2013) 346.

[15]E. Ukar, A. Lamikiz, S. Martínez, F. Estalayo, I. Tabernero: Procedia Eng., 63, (2013) 53.

[16] W. Guo, M. Hua, P.W. Tse and A.C.K. Mok: Int. J. Adv. Manuf. Technol., 59, (2012) 1009.

(Received: July 9, 2016, Accepted: November 15, 2016) 